\title{
Foci of Stagonospora Nodorum Blotch in Winter Wheat Before Canopy Development
}

\author{
Denis A. Shah, Gary C. Bergstrom, and Peter P. Ueng
}

First and second authors: Department of Plant Pathology, Cornell University, Ithaca, NY 14853; and third author: USDA-ARS, Plant Molecular Biology Laboratory, Beltsville, MD 20705.

Accepted for publication 25 March 2001.

\begin{abstract}
Shah, D. A., Bergstrom, G. C., and Ueng, P. P. 2001. Foci of Stagonospora nodorum blotch in winter wheat before canopy development. Phytopathology 91:642-647.

Stagonospora nodorum blotch (SNB) often develops explosively on upper leaves and glumes of wheat. Inoculum for late season infections may arise from early disease foci in the lower canopy or from recent immigration of wind-dispersed ascospores. Research was conducted to determine if foci of SNB are present and secondary spread has occurred in fields before tiller elongation. We determined the incidence of infec-

Multilocus restriction fragment length polymorphism haplotypes were determined for each isolate. Of 55 isolates collected from one field, there were 22 distinct haplotypes. Diseased plants were aggregated in both fields; aggregates sometimes extended to adjacent quadrats. Plants within aggregates were often infected by the same haplotype, suggesting that secondary spread had occurred. Foci overlapped because some aggregates were infected by more than one haplotype. Our results show that genetically diverse populations of $S$. nodorum were already established in fields before canopy development and were comprised of sometimes overlapping foci undergoing clonal expansion.
\end{abstract} tion by Stagonospora nodorum for plants sampled at the mid-tillering stage in $961-\mathrm{m}^{2}$ quadrats in each of two fields. Isolates of $S$. nodorum were recovered from 32 quadrats, one per infected plant where possible.
Additional keywords: beta-binomial, randomization testing.
Stagonospora nodorum blotch (SNB) is a foliar and glume disease affecting wheat (Triticum aestivum L.). It is caused by the fungus Stagonospora nodorum (Berk.) E. Castell. \& Germano (syn. Septoria nodorum [Berk.] Berk. in Berk. \& Broome; teleomorph Phaeosphaeria nodorum [E. Müll.] Hedjar., syn. Leptosphaeria nodorum E. Müll.). Infection of the upper leaves and glumes during grain formation is responsible for appreciable reductions in grain yield (13). Severe disease is associated with wet weather during tiller elongation through grain filling (32) and often seems explosive, indicating a sudden exposure of leaves to large amounts of inoculum. It is unknown when inoculum becomes available for late season infection. Disease management strategies may differ for early versus late arriving primary inoculum.

If inoculum for late season infections arise from early disease foci in the lower canopy then the disease should be present in the field prior to the beginning of tiller elongation. Quantifying SNB before tiller elongation is a difficult task, because symptoms are nondescript and indistinguishable from normal leaf senescence. Given this constraint, measuring disease incidence (presence or absence of disease) is much more feasible and practical than attempts at assessing disease severity.

Appropriate disease assessments should acknowledge the spatial distribution of SNB, which, to our knowledge, has never been quantified before tiller elongation. There are several methods for characterizing the spatial pattern of disease incidence data (9). Not all are appropriate for assessing SNB spatial pattern in wheat. Wheat is a high-density crop (200 to $600^{+}$plants per square

Corresponding author: G.C. Bergstrom; E-mail address: gcb3@ cornell.edu

Publication no. P-2001-0416-01R

This article is in the public domain and not copyrightable. It may be freely reprinted with customary crediting of the source. The American Phytopathological Society, 2001. meter). Quadrat-based methods and statistical distributional approaches using sparse sampling (9) are more appropriate for quantifying SNB spatial pattern. Characterizing spatial pattern for quadrat-based data requires more than one method of analysis (15). Distributional approaches are useful for determining spatial associations in incidence at or below the quadrat scale, whereas spatial autocorrelation analyses can be used to determine spatial association at or above the quadrat scale (34).

One would expect the incidence of SNB to be aggregated because pycnidiospores of Stagonospora nodorum are splash dispersed (16). However, the relatively long winter wheat growing season (September to July in New York) provides many opportunities for secondary cycles of infection. The pattern of disease incidence may thus appear random as individual foci merge. In such a situation, spatial spread cannot be observed from disease incidence data alone (27). S. nodorum is, however, a genetically diverse pathogen $(12,22)$ and isolates can be identified genotypically $(12,35)$. It is therefore possible to determine the underlying population (characterized genetically) responsible for an observed spatial pattern of disease incidence. A combination of statistical and population genetical approaches to spatial analysis can help elucidate the extent of spatial spread.

The objectives of this research were to (i) determine whether SNB foci were present and prevalent prior to canopy development, and (ii) determine if there was clonal spread of SNB (enlargement of foci) before canopy development.

\section{MATERIALS AND METHODS}

Field sites. Two 0.5-ha fields were sown to the same seed lot of winter wheat cv. Geneva in September 1995. The incidence of infection in untreated seed was $2 \%$ as determined by assaying 400 seed on $S$. nodorum agar for wheat medium (21). Spatial spread can be seen only when there are sparse initial infections (6). Therefore, seed were treated with triadimenol, Baytan $30 \mathrm{~F}$ at $0.98 \mathrm{ml} \mathrm{kg}^{-1}$, 
based on previous research (10), and seed transmission was presumed to be reduced (to a fraction of $1 \%$ ) but not completely eliminated. The first field was located at the Reynolds Game Farm, Ithaca, NY, and the second at the Robert Musgrave Research Farm, Aurora, NY. These fields were $35.3 \mathrm{~km}$ apart. The Ithaca field was sown on 14 September 1995, and the Aurora field the next day. The sowing rate was $150 \mathrm{~kg} \mathrm{ha}^{-1}$ at 20 -cm-row spacings. Fields had not been in wheat for at least 1 year prior to the experiment. Rows were oriented north-south $(\mathrm{N}-\mathrm{S})$ at Ithaca and west-east (W-E) at Aurora. Plant density (number of plants per square meter) was determined by counting all plants within four arbitrarily chosen 30 -cm-row sections in each field in April 1996.

Within-field sampling. Due to below normal spring temperatures in 1996, plants did not initiate tiller elongation until midMay. Plants were sampled at essentially the same growth stage (GS) (37), from the Ithaca field on 18 April (GS 24) and the Aurora field on 14 May (GS 23). Within each field, samples were obtained at four spatially separated sites, each consisting of two, perpendicular, intersecting transects, one in the N-S and the other in the W-E direction. Ten plants within a $1-\mathrm{m}^{2}$ area were removed at distances of $1,2,4,6,8$, and $10 \mathrm{~m}$ in each of the four cardinal directions measured from the point of intersection of the transects. Plants were placed in brown paper bags and air-dried at room temperature in the laboratory. Dried samples were stored at $5^{\circ} \mathrm{C}$ until they could be analyzed further.

Five to six necrotic or chlorotic leaf pieces (2 to $3 \mathrm{~cm}$ in length) were removed from each sampled plant, surface disinfested as described previously (30), and incubated under near-ultraviolet light (12-h photoperiod) to induce the production of pycnidia of $S$. nodorum. A plant was scored positive for incidence of infection by $S$. nodorum if pycnidia of the fungus developed on at least one of the incubated leaf pieces.

Fungal isolations. $S$. nodorum was isolated from infected leaf pieces by transferring part of the exuded cirrhus from a single pycnidium onto V8-juice agar (200 $\mathrm{ml}$ of V8 juice, $3 \mathrm{~g}$ of $\mathrm{CaCO}_{3}$, and $15 \mathrm{~g}$ of agar per $800 \mathrm{ml}$ of distilled water) containing streptomycin. Our goal was to obtain one isolate per infected plant. Isolates were not successfully recovered from all infected plants.

Because $S$. nodorum populations are so genetically diverse, clonality can be difficult to detect by fingerprinting (3). Therefore, we used a fairly simple restriction fragment length polymorphism (RFLP) system to identify isolates. EcoRI-digested fungal genomic DNA was hybridized to probes $6,16,45,60,74$, and 153 (35). Multiple haplotypes (defined as unique RFLP banding patterns) were observed with each probe (35). The pattern of hybridization for each probe was considered an allele. Alleles were recorded as positive integers, with zero representing alleles defined as the absence of any RFLP bands with the given probe. A multilocus haplotype was defined by the six-digit number representing the combination of alleles observed with all six probes.

Point pattern analysis. When sampling is quadrat-based, the variance in the number of diseased plants per quadrat is an indication of the extent of aggregation of disease incidence. A quadrat was defined as the $1-\mathrm{m}^{2}$ area within which $n$ individual plants were each evaluated for disease incidence. The binary form of the index of dispersion $(D)(9,18)$ was calculated for the counts of the number of diseased plants per quadrat, using all sampled quadrats $(N=101$ for each field). Values of $D>1$ suggest aggregation, because the observed variance of disease incidence is inflated above the expected binomial variance (termed overdispersion in the literature) (5). The quantity $(N-1) \cdot D$ has a $\chi^{2}$ distribution $(N-1 \mathrm{df})$ under the null hypothesis that disease incidence is randomly distributed (9). The $C_{(\alpha)}$ statistic was calculated to test whether overdispersion was characterized specifically by the beta-binomial distribution (18). Test statistics were calcu- lated using the BBD software program (17). Formulas for calculating these statistics when the sample sizes are uneven (as with these data sets) are presented by Madden et al. (20).

A good fit of the binomial distribution (parameters $[n, \pi]$ ) to disease incidence data indicates that the pattern of disease incidence is random. If the beta-binomial distribution (parameters $[n$, $p, \theta]$ ) fits the data, then disease incidence is clustered. The pattern of disease is random when $\theta=0$. The beta-binomial parameter $\theta$ is related to the intracluster correlation coefficient, $\rho$, because $\rho=$ $\theta /(1+\theta)$. The parameter $\rho$ is a measure of the tendency of individual plants within the same quadrat to have the same disease status. Thus, $\theta$ and $\rho$ increase as clustering increases at the scale of the quadrat or below (18). The BBD software program was used to fit the binomial and beta-binomial distributions to disease incidence data. Estimates of the beta-binomial parameter $\hat{\theta}$ were tested for their difference from zero using $t$ tests (18). A likelihood ratio test was done to determine whether the beta-binomial provided a better fit to the data than the binomial distribution (34). The $\chi^{2}$ goodness-of-fit statistic was calculated for assessing the fit of both the binomial and beta-binomial distributions to the observed data. This was possible only for the Ithaca data set, because observed and expected frequency classes for the Aurora data set were too few after pooling (8).

In phytopathosystems examined to date, $\theta$ has been observed to vary with $p$ (19). The easiest way to examine this relationship is through the binary form of Taylor's power law (7), which was fit to counts of the number of diseased plants per quadrat. The equation is given by

$$
V_{\mathrm{obs}}=A_{x} v^{b}{ }_{\text {bin }}
$$

where $v_{\mathrm{obs}}$ is the observed variance in the number of diseased plants per quadrat, and $v_{\text {bin }}$ is the variance assuming the number of diseased plants per quadrat is distributed binomially. $A_{x}$ and $b$ are parameters that can be estimated by linear regression after linearizing equation 1 by taking logarithms. The estimated values of $A_{x}$ and $b$ reveal whether $\theta$ (and hence $\rho$ ) varies with mean disease incidence (19). Each sampled site within a field (consisting of 24 quadrats) was treated as an independent data set. Data sets were pooled across both the Aurora and Ithaca fields to provide eight data sets for the analysis.

Spatial analysis by distance indices. Point pattern analyses are useful for quantifying spatial associations at or below the scale of the sampling quadrat, but do not reveal any information on spatial pattern above the quadrat level. Spatial correlation methods are useful for analyzing spatial structure at levels above that of the sampling quadrat. Spatial analysis by distance indices (SADIE) is a relatively new form of spatial correlation analysis that is conditioned on the existing heterogeneity of disease counts within a specified area. SADIE may be more appropriate than spatial autocorrelation analyses for discrete data characterized by many zero counts, such as the present data sets (28). SADIE has been previously applied to counts of diseased individuals per sampling unit in a phytopathological setting $(33,34)$. Analyses were done with software supplied by J. N. Perry (Dept. of Entomology and Nematology, Rothamsted Experimental Station, U.K). The index of aggregation, $I_{a}$, provides an overall description of aggregation among quadrats (28). Values of $I_{a}>1$ suggest an aggregated pattern of diseased plants among sampled quadrats. The significance level of the observed value of $I_{a}$ is determined by a form of randomization testing. With this method, the observed value of the statistic is compared with its distribution under the null hypothesis of randomness. The null distribution is generated by repeated permutation of the observed data set so observations are randomly assigned to sampled locations. Permutations were done 5,967 times for each SADIE test in the present study. Mean disease incidence per quadrat was converted to expected counts of diseased plants per 100 to prevent bias resulting from uneven sample sizes among quadrats. 


\section{RESULTS}

Point pattern analysis. Figures 1 and 2 show the incidence of plants infected by $S$. nodorum at four sampling sites in the fields at Aurora and Ithaca, respectively. At Aurora, no diseased plant was recovered from 82 of the 96 sampled quadrats along transects (Fig. 1). The incidence of diseased plants was approximately 10 times higher at Ithaca $(\hat{\pi}=0.19)$ than at Aurora $(\hat{\pi}=0.02)$. Plant stand was twice as dense at Ithaca as at Aurora (490 versus
250 plants per $\mathrm{m}^{2}$ ). The variance in disease incidence per quadrat was greater than that expected, assuming incidence was distributed randomly for both Aurora $(D=2.09 ; P<0.0001)$ and Ithaca $(D=3.38 ; P<0.0001)$. Disease incidence was characterized by the beta-binomial distribution in both fields $\left(P<0.001 ; C_{(\alpha)}\right.$ test $)$. Estimates of the beta-binomial parameter $\theta$ were significantly different from zero at both Aurora ( $\hat{\theta}=0.10 ; t=2.01 ; P<0.024)$ and Ithaca $(\hat{\theta}=0.33 ; t=4.79 ; P<0.0001)$, indicating that the incidence of plants infected by $S$. nodorum was clustered at the
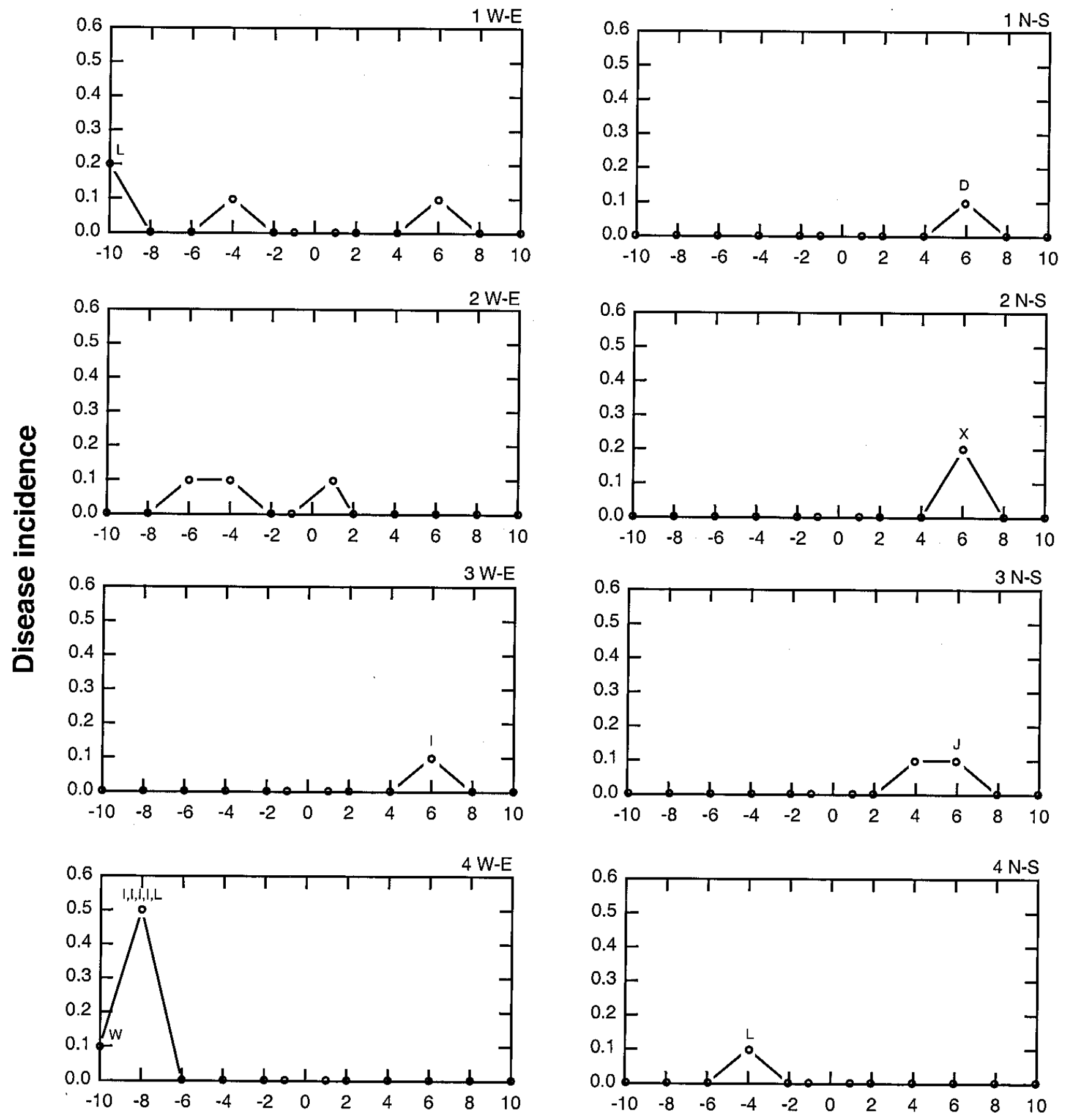

\section{Distance from center $(\mathrm{m})$}

Fig. 1. Incidence of infection of wheat plants by Stagonospora nodorum at Aurora along two 20-m-perpendicular transects (north-south [N-S] and west-east [W-E]) at four within-field sites (1 to 4). The $x$ axis represents distance in meters from the point of intersection of the two transects. Disease incidence was assessed at tillering. Multilocus haplotypes (alphabetical labels) of $S$. nodorum isolates recovered from infected plants are shown adjacent to the disease incidence plot symbols. Each label represents a single isolate. 
quadrat level or below. The intracluster correlation parameter $\rho$ indicated the same, because $\rho>0$ for both fields, but was 2.7 times higher at Ithaca $(\hat{\rho}=0.25)$ than at Aurora $(\hat{\rho}=0.09)$. The betabinomial fit the observed data better than the binomial distribution in both fields, based on the likelihood ratio test $(P<0.01)$. The $\chi^{2}$ goodness-of-fit test, comparing the fit of the observed frequencies with those expected with the binomial and betabinomial distributions, was done for the subset of quadrats for which $n=10$. The test was possible for the Ithaca data set only. This data set was described by the beta-binomial distribution $\left(\chi^{2}=2.063 ; P=0.724\right)$ but not by the binomial distribution $\left(\chi^{2}=\right.$ 69.409; $P<0.0001)$.

The incidence of diseased plants per quadrat was well described by the linearized form of the binary power law $\left(R^{2}=0.94\right.$; Fig. 3$)$. Clustering of disease incidence was significant across all eight sites, because a $t$ test indicated that $\ln \left(A_{x}\right)(=1.013 ; \mathrm{SE}=0.166)$ was significantly greater than zero $(P=0.0004)$. The parameter $b$ $(=1.37$; SE $=0.135)$ may not be greater than one $(P=0.0169)$, which indicates that the degree of clustering may be independent of mean disease incidence. However, this result should be inter-
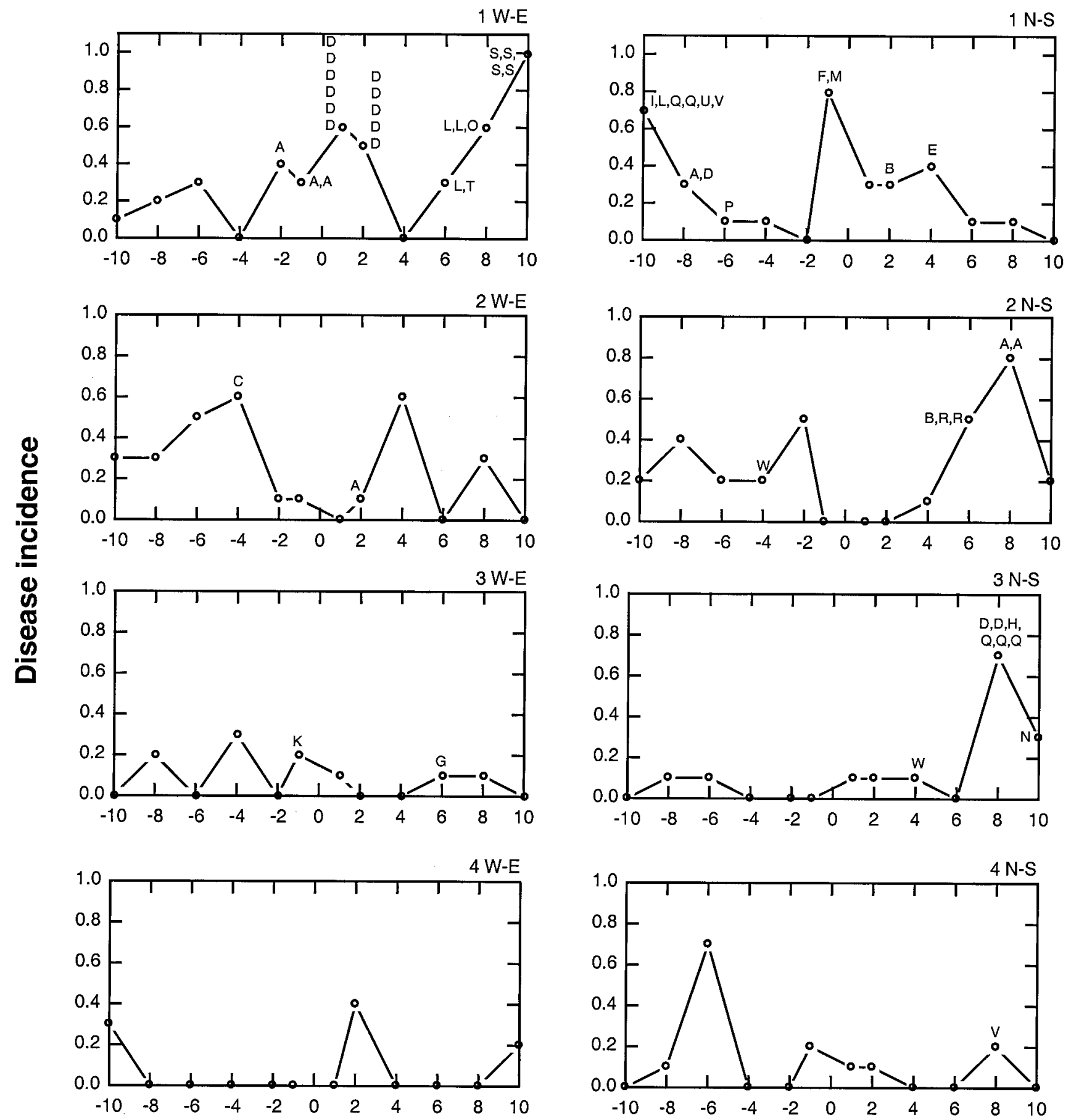

\section{Distance from center $(\mathrm{m})$}

Fig. 2. Incidence of infection of wheat plants by Stagonospora nodorum at Ithaca along two 20-m-perpendicular transects (north-south [N-S] and west-east [W-E]) at four within-field sites (1 to 4). The $x$ axis represents distance in meters from the point of intersection of the two transects. Disease incidence was assessed at tillering. Multilocus haplotypes (alphabetical labels) of $S$. nodorum isolates recovered from infected plants are shown adjacent to the disease incidence plot symbols. Each label represents a single isolate. 
preted cautiously, in light that only eight data points were available for the binary power law analysis. The beta-binomial parameter $\theta$ and the intracluster correlation coefficient $\rho$ were calculated as 0.242 and 0.195 , respectively, assuming 10 sampled plants per quadrat (19).

SADIE. There was no evidence of aggregation above the quadrat level in the Aurora field $\left(I_{a}=0.54 ; P=0.93\right)$. For the Ithaca field, however, results strongly indicated that aggregates of diseased plants extended beyond the quadrat $\left(I_{a}=2.00 ; P=0.0002\right)$.

Multilocus haplotype spatial pattern. The spatial pattern of recovered isolates is represented in Figures 1 and 2. Only 12 isolates of $S$. nodorum were recovered from plant samples from Aurora (Table 1; Fig. 1), whereas 55 isolates were obtained from the Ithaca field (Table 1; Fig. 2).

The aggregation of multilocus haplotypes is visually obvious. The only multilocus haplotypes recovered five or more times at the Ithaca site were A, D, and Q (Table 1). These multilocus haplotypes were recovered within the same quadrat and at distances greater than $30 \mathrm{~m}$ apart (Fig. 2). Multilocus haplotype $\mathrm{S}$ was recovered four times; all four isolates were sampled from the same quadrat (Fig. 2). More than one multilocus haplotype was recovered from seven of the quadrats; in one such instance, five different multilocus haplotypes were found on six different plants sampled from the same quadrat (Fig. 2).

\section{DISCUSSION}

SNB was already present in wheat fields before tiller elongation and before there were any typical symptoms of the disease. The incidence of plants with SNB was aggregated at a scale less than $1 \mathrm{~m}^{2}$ because of secondary disease spread, but in some instances, aggregates could consist of infections due to more than one pathogen genotype. Therefore, there was a genetically diverse population of $S$. nodorum, initiated from foci potentially within centimeters of each other, which was sufficient to start an epidemic of SNB in the upper canopy.

Point pattern analysis and distributional statistics showed that the incidence of wheat plants infected by S. nodorum before tiller

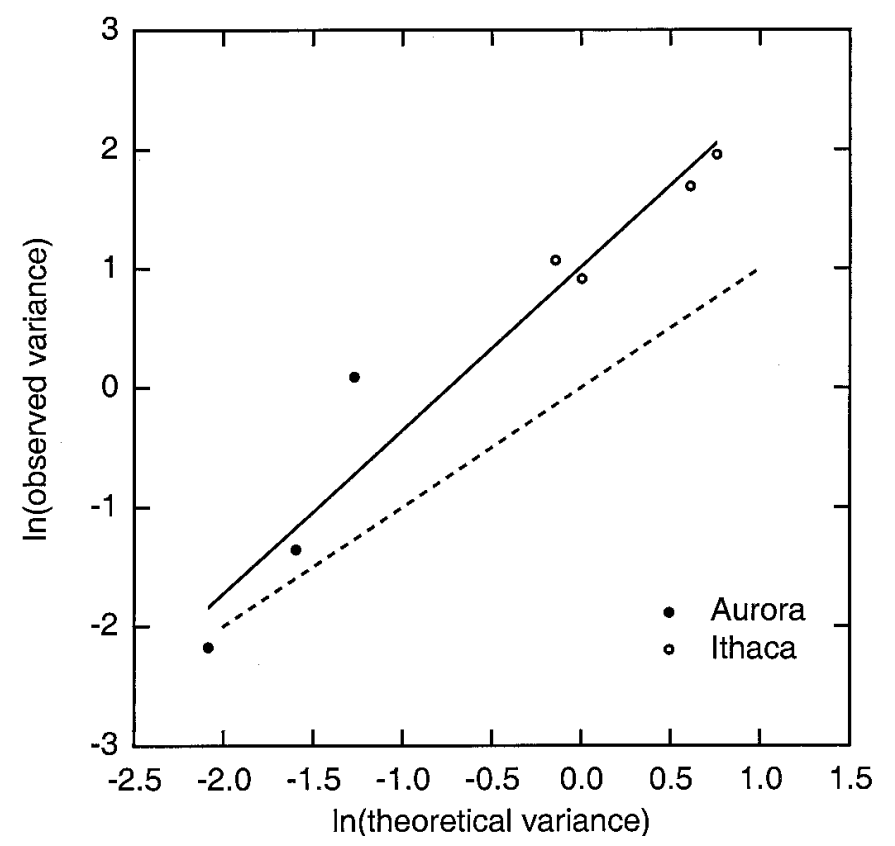

Fig. 3. Relationship between the observed and theoretical (binomial) variances in the number of Stagonospora nodorum-infected plants per quadrat. Data represent eight sites within two fields (Aurora and Ithaca). The dotted line represents the situation where the observed variance is exactly binomial. elongation was aggregated within quadrats. SADIE analysis demonstrated that, at least in some instances, aggregates of $S$. nodorum-infected plants extended to adjacent quadrats. The spatial pattern of recovered $S$. nodorum isolates suggested that, in some instances, aggregates of plants infected by $S$. nodorum were comprised of several merged foci established by different pathogen haplotypes. The data are consistent with the hypothesis that foliar epidemics of SNB are initiated from a genetically diverse population of $S$. nodorum, with initial foci potentially as close together as a few centimeters. The index of haplotypic diversity (25) at the Ithaca field $(H=0.93)$ is reflective of the genetic diversity in $S$. nodorum populations reported in previous studies $(4,11,12,22,24)$.

Further epidemic development by clonal spread did not appear to extend much beyond 1 to $2 \mathrm{~m}$ before the beginning of tiller elongation. $S$. nodorum is dispersed by rain-splashed pycnidiospores. Fungal diseases spread by splash dispersal are expected to show aggregation because spores are splashed only a few centimeters (16). In rain tower experiments, $S$. nodorum pycnidiospores were dispersed up to $4 \mathrm{~m}$ (2). The relatively long winter wheat growing season provides frequent opportunities for pathogen dissemination (either in the fall or early spring), which could obscure spatial aggregates of SNB incidence. A low leaf area index (hence limited canopy structure) is characteristic of wheat before tiller elongation (29), providing little hindrance to the splash dispersal of pycnidiospores $(1,26)$. Once tiller elongation begins, a rapidly developing canopy could block the further horizontal progress of SNB, though its continued vertical progression is essential for infection of flag leaves and ears.

Foliar epidemics of SNB do not rely solely on immigrant $P$. nodorum ascospores arriving after canopy closure. Foci present at crop phenological stages before tiller elongation could be initiated by one of two mechanisms: transmission of $S$. nodorum from infected seed $(30,31)$, or immigrant ascospores in the fall or early spring (36). $S$. nodorum isolates from other grasses are not highly virulent on wheat (14) and are probably not a significant inoculum source. Seed transmission and immigrant ascospores would both establish initial foci that are spatially random. It is less clear

TABLE 1. Frequency of multilocus haplotypes of Stagonospora nodorum isolates recovered from the foliage of winter wheat fields at Aurora and Ithaca ${ }^{a}$

\begin{tabular}{|c|c|c|c|}
\hline Multilocus haplotype ${ }^{b}$ & Designation & Aurora foliage & Ithaca foliage \\
\hline 421111 & A & $\ldots$ & 7 \\
\hline 321122 & B & $\ldots$ & 2 \\
\hline 321112 & $\mathrm{C}$ & $\ldots$ & 1 \\
\hline 021411 & $\mathrm{D}$ & 1 & 14 \\
\hline 521213 & $\mathrm{E}$ & $\ldots$ & 1 \\
\hline 421012 & $\mathrm{~F}$ & $\ldots$ & 1 \\
\hline 021412 & $\mathrm{G}$ & $\ldots$ & 1 \\
\hline 321211 & $\mathrm{H}$ & $\ldots$ & 1 \\
\hline 421121 & I & 5 & 1 \\
\hline 021521 & $\mathrm{~J}$ & 1 & $\ldots$ \\
\hline 121112 & $\mathrm{~K}$ & $\ldots$ & 1 \\
\hline 021421 & $\mathrm{~L}$ & 3 & 4 \\
\hline 021422 & M & $\ldots$ & 1 \\
\hline 221222 & $\mathrm{~N}$ & $\ldots$ & 1 \\
\hline 003461 & $\mathrm{O}$ & $\ldots$ & 1 \\
\hline 004421 & $\mathrm{P}$ & $\ldots$ & 1 \\
\hline 023411 & Q & $\ldots$ & 5 \\
\hline 023412 & $\mathrm{R}$ & $\ldots$ & 2 \\
\hline 401111 & $\mathrm{~S}$ & $\ldots$ & 4 \\
\hline 301211 & $\mathrm{~T}$ & $\ldots$ & 1 \\
\hline 423121 & $\mathrm{U}$ & $\ldots$ & 1 \\
\hline 023441 & V & $\ldots$ & 2 \\
\hline 401121 & W & 1 & 2 \\
\hline 101122 & $X$ & 1 & $\ldots$ \\
\hline
\end{tabular}

a Both fields had been sown to the same seed lot. Number of isolates of the given haplotype recovered from sampled plants at Aurora and Ithaca.

b Multilocus haplotype determined by hybridization of restriction fragment length polymorphism fragments to probes $6,16,45,60,74$, and 153 (35). 
whether seed transmission of $S$. nodorum could establish a foliar population that is as genetically diverse as the foliar populations characterized thus far. In the present study, seed were harvested from the Aurora field. The incidence of seed infection was $7.8 \%$. Thirty isolates of $S$. nodorum were recovered from infected seed, of which 17 were unique multilocus haplotypes $(H=0.93)$ (data not shown). Other than this observation, we know of no complete studies to date examining the genotypic diversity in seedborne $S$. nodorum populations.

Population genetics can complement the traditional tools of epidemiology (e.g., spatial analysis, modeling, pathotype differentiation, and spore trapping). Conscious attempts are needed to integrate these two disparate fields to realize the potential benefits (23). We integrated the tools of epidemiology and population genetics to demonstrate the establishment of SNB before canopy development. Population genetic analyses combined with traditional epidemiology will further assist work to rigorously assess the relative contribution of seedborne versus ascospore sources of primary inoculum in field epidemics of SNB.

\section{ACKNOWLEDGMENTS}

This research was supported in part by Cornell University Hatch Project NYC-153472 and by USDA-ARS CRIS. D. A. Shah received a Graduate Research Assistantship from the Department of Plant Pathology, Cornell University. We thank M. G. Milgroom for critical comments on the manuscript.

\section{LITERATURE CITED}

1. Boudreau, M. A., and Madden, L. V. 1995. Effect of strawberry density on dispersal of Colletotrichum acutatum by simulated rain. Phytopathology 85:934-941.

2. Brennan, R. M., Fitt, B. D. L., Taylor, G. S., and Colhoun, J. 1985. Dispersal of Septoria nodorum pycnidiospores by simulated rain and wind. Phytopathol. Z. 112:291-297.

3. Brygoo, Y., Caffier, V., Carlier, J., Fabre, J. V., Fernandez, D., Giraud, T., Mourichon, X., Neema, C., Notteghem, J. L., Pope, C., Tharreau, D., and Lebrun, M. H. 1998. Reproduction and population structure in phytopathogenic fungi. Pages 133-148 in: Molecular Variability of Fungal Pathogens. P. Bridge, Y. Couteaudier, and J. Clarkson, eds. CAB International, Wallingford, U.K.

4. Caten, C. E., and Newton, A. C. 2000. Variation in cultural characteristics, pathogenicity, vegetative compatibility and electrophoretic karyotype within field populations of Stagonospora nodorum. Plant Pathol. 49:219-226.

5. Collett, D. 1991. Modeling Binary Data. Chapman and Hall, London.

6. Colwell, R. N. 1956. Determining the prevalence of certain cereal crop diseases by means of aerial photography. Hilgardia 26:223-256.

7. Hughes, G., and Madden, L. V. 1992. Aggregation and incidence of disease. Plant Pathol. 41:657-660.

8. Hughes, G., and Madden, L. V. 1993. Using the beta-binomial distribution to describe aggregated patterns of disease incidence. Phytopathology 83:759-763.

9. Hughes, G., McRoberts, N., Madden, L. V., and Nelson, S. C. 1997. Validating mathematical models of plant-disease progress in space and time. IMA J. Math. Appl. Med. Biol. 14:85-112.

10. Kalb, D. W., and Bergstrom, G. C. 1996. Effects of seed treatment on seedborne Septoria nodorum blotch and yield of winter wheat in New York, 1995. Fungic. Nematic. Tests 51:315.

11. Keller, S. M., McDermott, J. M., Pettway, R. E., Wolfe, M. S., and McDonald, B. A. 1997. Gene flow and sexual reproduction in the wheat glume blotch pathogen Phaeosphaeria nodorum (anamorph Stagonospora nodorum). Phytopathology 87:353-358.

12. Keller, S. M., Wolfe, M. S., McDermott, J. M., and McDonald, B. A.
1997. High genetic similarity among populations of Phaeosphaeria nodorum across wheat cultivars and regions in Switzerland. Phytopathology 87:1134-1139.

13. King, J. E., Cook, R. J., and Melville, S. C. 1983. A review of Septoria diseases of wheat and barley. Ann. Appl. Biol. 103:345-373.

14. Krupinsky, J. M. 1997. Aggressiveness of Stagonospora nodorum isolates from perennial grasses on wheat. Plant Dis. 81:1032-1036.

15. Madden, L. V. 1989. Dynamic nature of within-field disease and pathogen distributions. Pages 96-126 in: Spatial Components of Plant Disease Epidemics. M. J. Jeger, ed. Prentice Hall, Englewood Cliffs, NJ.

16. Madden, L. V. 1992. Rainfall and the dispersal of fungal spores. Adv. Plant Pathol. 8:39-79.

17. Madden, L. V., and Hughes, G. 1994. BBD - Computer software for fitting the beta-binomial distribution to disease incidence data. Plant Dis. 78:536-540.

18. Madden, L. V., and Hughes, G. 1995. Plant disease incidence: Distributions, heterogeneity, and temporal analysis. Annu. Rev. Phytopathol. 33:529-564.

19. Madden, L. V., and Hughes, G. 1999. Sampling for plant disease incidence. Phytopathology 89:1088-1103.

20. Madden, L. V., Hughes, G., and Ellis, M. A. 1995. Spatial heterogeneity of the incidence of grape downy mildew. Phytopathology 85:269-275.

21. Manandhar, J. B., and Cunfer, B. M. 1991. An improved selective medium for the assay of Septoria nodorum from wheat seed. Phytopathology 81:771-773.

22. McDonald, B. A., Miles, J., Nelson, L. R., and Pettway, R. E. 1994. Genetic variability in nuclear DNA in field populations of Stagonospora nodorum. Phytopathology 84:250-255.

23. Milgroom, M. G., and Fry, W. E. 1997. Contributions of population genetics to plant disease epidemiology and management. Adv. Bot. Res. 24:1-30.

24. Murphy, N. E., Loughman, R., Appels, R., Lagudah, E. S., and Jones, M. G. K. 2000. Genetic variability in a collection of Stagonospora nodorum isolates from Western Australia. Aust. J. Agric. Res. 51:679-684.

25. Nei, M., and Tajima, F. 1981. DNA polymorphism detectable by restriction endonucleases. Genetics 97:145-163.

26. Ntahimpera, N., Ellis, M. A., Wilson, L. L., and Madden, L. V. 1998. Effects of a cover crop on splash dispersal of Colletotrichum acutatum conidia. Phytopathology 88:536-543.

27. O’Hara, R. B., and Brown, J. K. M. 1998. Movement of barley powdery mildew within field plots. Plant Pathol. 47:394-400.

28. Perry, J. N. 1998. Measures of spatial pattern for counts. Ecology 79: 1008-1017.

29. Rickman, R. W., and Rasmussen, P. E. 1985. Ground cover estimates for seedling cereal crops. Soil Sci. Soc. Am. J. 49:1251-1255.

30. Shah, D., Bergstrom, G. C., and Ueng, P. P. 1995. Initiation of Septoria nodorum blotch epidemics in winter wheat by seedborne Stagonospora nodorum. Phytopathology 85:452-457.

31. Shah, D. A., and Bergstrom, G. C. 2000. Temperature dependent seed transmission of Stagonospora nodorum in wheat. Eur. J. Plant Pathol. 106:837-842.

32. Shaw, M. W. 1999. Epidemiology of Mycosphaerella graminicola and Phaeosphaeria nodorum: An overview. Pages 93-97 in: Septoria and Stagonospora Diseases of Cereals: A Compilation of Global Research. M. van Ginkel, A. McNab, and J. Krupinsky, eds. International Maize and Wheat Improvement Center, Mexico D.F., Mexico.

33. Turechek, W. W., and Madden, L. V. 1999. Spatial pattern analysis and sequential sampling for the incidence of leaf spot on strawberry in Ohio. Plant Dis. 83:992-1000.

34. Turechek, W. W., and Madden, L. V. 1999. Spatial pattern analysis of strawberry leaf blight in perennial production systems. Phytopathology 89:421-433.

35. Ueng, P. P., Bergstrom, G. C., Slay, R. M., Geiger, E. A., Shaner, G., and Scharen, A. L. 1992. Restriction fragment length polymorphisms in the wheat glume blotch fungus, Phaeosphaeria nodorum. Phytopathology 82:1302-1305.

36. Verreet, J.-A. 1995. Principles of integrated pest management: The IPM wheat model. Pflanzenschutz-Nachr. Bayer 48:1-307.

37. Zadoks, J. C., Chang, T. T., and Konzak, C. F. 1974. A decimal code for the growth stages of cereals. Weed Res. 14:415-421. 